\title{
Picture sequencing by schizophrenic patients
}

\author{
WILLIAM W. BEATTY \\ University of Oklahoma Health Sciences Center, Oklahoma City, Oklahoma \\ ZELJKO JOCIC \\ Veterans Affairs Medical Center, Fargo, North Dakota \\ and \\ NANCY MONSON \\ Neuropsychiatric Research Institute, Fargo, North Dakota
}

\begin{abstract}
Cognitive sequencing by community-dwelling schizophrenic patients was studied using a new test of picture sequencing designed to minimize the influence of information-processing speed, visual perception and scanning, manual dexterity and motor speed, and knowledge of social conventions on test scores. Compared with age- and education-equated normal community controls, more than $50 \%$ of the schizophrenic patients exhibited deficits on the picture sequencing test.
\end{abstract}

The ability to perform actions in appropriate temporal sequence is a fundamental cognitive skill necessary for success in a wide range of activities of daily living. Likewise, the ability to detect when events or actions are "out of order' can provide essential information that can lead to modification of behavior in a manner likely to lead to adaptive responding.

The most commonly used test of cognitive sequencing is the Picture Arrangement (PA) subtest of the Wechsler Intelligence Test battery (Wechsler, 1981). On the PA test, subjects are required to arrange 3-6 cartoon sketches depicting characters engaged in various activities in temporal order so that the sequence of drawings "tells a story." Although there is little doubt that the PA test measures cognitive sequencing, under the usual conditions of administration, the obtained score is influenced by several other cognitive abilities. These include: (1) the ability to process information rapidly, since the test score is mainly determined by the number of bonus points awarded for swift, accurate solutions; (2) visuoperceptual and visual scanning ability, since a high score requires rapidly resolving details of the drawings, which are rather small, and quickly shifting attention from one drawing to another; (3) manual dexterity, since subjects must rearrange the drawings in order as rapidly as possible; (4) the ability to interpret information presented in a novel format quickly and accurately; and (5) a reasonable degree of social sophistication, since the cartoons depict scenarios of human interactions drawn from everyday experience. Because human experiences are not uniform, alternative correct solutions are allowed for some items on the PA test. However, as Lezak (1983) points out, other orderings of

Please address all correspondence and reprint requests to William W. Beatty, Center for Alcohol and Drug Related Studies, Department of Psychiatry and Behavioral Sciences, University of Oklahoma Health Sciences Center, P.O. Box 26901, Oklahoma City, OK 73190. the drawings that are perfectly reasonable, given an individual's past experience, are scored "wrong."

Previous research with schizophrenic patients has shown consistent impairment on the PA test (Heaton, Baade, \& Johnson, 1978), but the interpretation of this deficit is not at all clear because of the complexity of the PA task. A vast literature demonstrates that schizophrenics process information slowly (Strauss, 1989), exhibit aberrations in eye-movement tracking (Levin, 1984; Thaker, Buchanan, Kirkpatrick, \& Tamminga, 1989) and in shifting and maintaining visual attention (Grillon, Courchesne, Ameli, Geyer, \& Braff, 1990; Posner, Early, Reiman, Pardo, \& Dhawan, 1988), perform manual tasks slowly (Heaton et al., 1978; Saykin et al., 1991), and display exceptionally poor knowledge of social conventions (Cutting $\&$ Murphy, 1990). Any one of these deficits could explain their poor performance on the PA test.

Difficulty in interpreting the sources of impairment on the PA test is by no means confined to research with schizophrenic and other psychotic populations. Patients with neurological diseases such as Parkinson's disease (PD) or multiple sclerosis (MS) process information slowly, display difficulties in visual perception, attention, and scanning, and perform manual tasks slowly and clumsily (Huber and Cummings, 1992; Rao, 1990). In a series of studies aimed at studying cognitive sequencing by PD and MS patients, we employed a picture sequencing test that is designed to circumvent some of the interpretative problems associated with the PA test. The picture sequencing test we devised is untimed and uses fairly large drawings of highly familiar scenarios (e.g., the growth of a person from birth to old age). The majority of the items do not depict human characters, so the test is minimally dependent on social knowledge.

In the present study, we examined picture sequencing by schizophrenics using the simplified test described above, which has previously proved sensitive to sequenc- 
ing deficits exhibited by patients with PD (Beatty \& Monson, 1990) or MS (Beatty \& Monson, 1992).

\section{METHOD}

\section{Subjects}

Twenty-one outpatients receiving treatment at Southeast Human Services Center, Fargo, North Dakota, and 24 age- and education-matched normal controls (12 men, 12 women) recruited from the community served as subjects. All subjects were paid for their participation and provided written informed consent after a thorough explanation of the procedures, which were approved by the local Institutional Review Board. Subjects with histories of severe medical disease, neurological disease, moderate or severe head injury, or major psychiatric illness other than schizophrenia or schizoaffective disorder for the patients were excluded. At the time of testing, no subject met DSM-III-R criteria for drug or alcohol abuse, although 13 of the patients had histories of known or suspected substance abuse.

On the basis of the results of the SCID-P version of the Structured Clinical Interview for DSM-III-R (Spitzer, Williams, Gibbon, \& First, 1988) conducted by Z.J., patients were classified as schizophrenic $(n=$ $10)$ or schizoaffective $(n=11)$. Of the 10 schizophrenic patients, three met DSM-III-R criteria for paranoid schizophrenia, and 7 were classified as undifferentiated. During the same session, Z.J. administered portions of a brief neurological examination (Buchanan \& Heinrichs, 1989) intended to identify patients who exhibited primitive reflexes (glabellar, snout, suck, or grasp), which are signs of organic brain damage. Throughout the study, all patients continued to receive medications (antipsychotic, antidepressant, anticholinergic) as prescribed by their attending psychiatrists, with doses adjusted for optimal clinical benefit. Although their disease was chronic, all patients were sufficiently well to reside successfully in the community with minimal assistance in activities of daily living provided by their case managers.

Preliminary analyses demonstrated that although the schizophrenic patients were significantly less well educated and attained lower scores on the SECIMS ( $p s<.02$ ) than did the schizoaffective patients, the two groups did not differ significantly on other demographic, clinical, or cognitive variables. Accordingly, the schizophrenic and schizoaffective groups were combined to form a single patient group ( 13 men, 8 women) that averaged 20.8 years of age at first episode (range $=13-28$ years), 6.8 hospitalizations (range $=1-22$ ), and 416.9 total days of hospitalization (range $=14-2,190$ ). At the time of examination, 8 patients exhibited primitive reflexes, and 14 were receiving anticholinergic agents. At the time of testing, mean daily neuroleptic dose was $662.9 \mathrm{mg}$ chlorpromazine equivalents (range $=100-1,800 \mathrm{mg}$ ). In addition, 5 patients were receiving lithium carbonate, 4 were receiving antiepileptics, 4 were receiving propranolol, and 4 were receiving antidepressants.

\section{Materials and Procedure}

The following tests were administered to all subjects.

Screening Examination for Cognitive Impairment in Multiple Sclerosis (SECIMS). This test is a modification of the Mini-Mental State Exam (MMSE; Folstein, Folstein, \& McHugh, 1975). The latter test has proved insensitive for identifying cognitive impairment in MS patients (see, e.g., Beatty \& Goodkin, 1990). The SECIMS is identical to the MMSE except that the number of words to be remembered is increased from three to seven, the two naming items (pencil, watch) are replaced by a 15item version of the Boston Naming Test (Kaplan, Goodglass, \& Weintraub, 1983), and the task of spelling "world" backwards (an alternative to serial $7 \mathrm{~s}$ in the MMSE) is not used. A sample of 52 normal controls, closely matched in terms of average and range in age, education, and gender to the population of MS patients served by our clinic, averaged $48.3 \pm 1.6$ (out of 51) on the SECIMS. A score below 46 (the fifth percentile for controls) on the SECIMS is highly suggestive of broad cognitive impairment as defined by performance on an extensive neuropsychological test battery (Goodkin, Beatty, \& Monson, 1990).

Picture sequencing test (Beatty \& Monson, 1990). On this test, subjects were required to arrange simple line drawings of familiar everyday scenes from left to right to make a coherent "story." Pictures were printed on $7.6 \times 12.7-\mathrm{cm}$ cards. First, the examiner demonstrated the principle of the test by rearranging a series of three pictures depicting a woman receiving a letter. The examiner also explained why the pictures were arranged in the correct order. Next, the subjects were given three practice trials, each consisting of three-picture sequences (filling a glass from a pitcher, a ball rolling down an incline, an apple falling from a tree). If a subject made an error, the examiner corrected the mistake and provided a verbal explanation of the principle. The test sequence consisted of 30 four-picture sequences: 15 involved changes in state (e.g., growth of a frog from a tadpole), and 15 involved changes in place (e.g., a truck passing through a tunnel). The test was not timed, and no feedback was given during the test series. If a subject indicated that he/she did not understand what was depicted, the examiner provided a brief cue (e.g., "it's a sculptor"). Because the scenes were highly familiar and the pictures were fairly large, such failures of visual recognition were rare. The examiner always arranged the cards in a set order for each trial, and it was always necessary to rearrange some of the cards to score a correct response. Failures to rearrange the cards were noted, but these errors occurred so infrequently that a statistical analysis was not warranted.

\section{RESULTS}

As shown in Table 1, the patients and controls were comparable in terms of age and education, but the patients performed more poorly than did the controls on the SECIMS, a measure of global mental status. The patients were impaired on the picture sequencing test, exhibiting deficits of roughly comparable magnitude when attempting to order pictures describing changes in state or place.

\section{DISCUSSION}

The present findings provide clear evidence of a substantial deficit in sequencing information by chronic schizophrenic outpatients. The test of picture sequencing employed in this study was not timed, used relatively large stimuli that were in continuous view of the subjects, and tapped highly familiar information that did not require more than minimal social knowledge. Therefore, it is unlikely that the patients' difficulties on the picture sequencing test can be attributed primarily to motor slowing, slowed information processing, lack of manual dexterity, failures of response initiation, impairments in anterograde or remote memory, deficits in visual perception or scanning, or lack of social knowledge. A subtle contribution of one or more of these factors cannot, of course, be ruled out definitively.

Correctly solving sequencing problems of the sort used here or on the PA subtest from the WAIS-R requires the capacity to direct, sustain, and shift attention, skills that are demonstrably impaired in the majority of schizophrenic patients (Grillon et al., 1990; Posner et al., 1988). An important question for subsequent research will be to deter-

Table 1

Demographic Characteristics and Neuropsychological Performance by Patients and Controls

\begin{tabular}{|c|c|c|c|c|c|}
\hline \multirow[b]{2}{*}{ Measure } & \multicolumn{2}{|c|}{ Patients } & \multicolumn{2}{|c|}{ Controls } & \multirow{2}{*}{$\begin{array}{c}F(1,43) \\
\text { for Groups }\end{array}$} \\
\hline & $M$ & $S D$ & $M$ & $\overline{S D}$ & \\
\hline Age (years) & 33.0 & 5.3 & 33.1 & 10.7 & 0.00 \\
\hline Education (years) & 13.0 & 2.1 & 13.4 & 1.3 & 0.51 \\
\hline SECIMS (points/51) & 43.8 & 3.4 & 47.8 & 1.9 & $24.61^{*}$ \\
\hline \multicolumn{6}{|c|}{ Picture Sequencing } \\
\hline State, points $/ 15$ & 13.4 & 1.8 & 14.8 & 0.5 & $12.59^{*}$ \\
\hline Place, points/15 & 11.6 & 3.3 & 14.2 & 0.8 & $13.63^{*}$ \\
\hline Total, points $/ 30$ & 25.0 & 4.6 & 29.1 & 0.9 & $17.88^{*}$ \\
\hline$N(\%)<28$ & 11 & 52 & 1 & 4 & \\
\hline
\end{tabular}

${ }^{*} p<.001$. 
mine the extent to which their pervasive attentional disturbances contribute to the impairments the majority of schizophrenic patients evidence on sequencing tests.

\section{REFERENCES}

Beatty, W. W., \& Goodkin, D. E. (1990). Screening for cognitive impairment in multiple sclerosis: An evaluation of the Mini-Mental State Exam. Archives of Neurology, 47, 297-301.

Beatty, W. W., \& Monson, N. (1990). Picture and motor sequencing in Parkinson's disease. Journal of Geriatric Psychiatry \& Neurology, 3, 192-197.

Beatty, W. W., \& Monson, N. (1992). Picture and motor sequencing in multiple sclerosis. Manuscript submitted for publication.

Buchanan, R. W., \& Heinrichs, D. W. (1989). The Neurological Evaluation Scale (NES): A structured instrument for the assessment of neurological signs in schizophrenia. Psychiatry Research, 27, 335-350.

CUTtING, J., \& MURPHY, D. (1990). Impaired ability of schizophrenics, relative to manics or depressives, to appreciate social knowledge about their culture. British Journal of Psychiatry, 157, 355-358.

Folstein, M. F., Folstein, S. E., \& McHugh, P. R. (1975). "MiniMental State"': A practical method for grading the cognitive state of patients for the clinician. Journal of Psychiatric Research, 12, 189-198.

GoOdkIN, D. E., BeAtTY, W. W., \& Monson, N. (1990, May). Screening examination for detecting cognitive impairment in patients with multiple sclerosis. Paper presented at the annual meeting of the Consortium of Multiple Sclerosis Centers, Denver, CO.

Grillon, C., Courchesne, E., Ameli, R., Geyer, M. A., \& BrafF, D. L. (1990). Increased distractibility in schizophrenic patients: Electrophysiologic and behavioral evidence. Archives of General Psychiatry, 47, 171-179.
Heaton, R. K., BAade, L. E., \& Johnson, K. L. (1978). Neuropsychological test patterns associated with psychiatric disorders in adults. Psychological Bulletin, 85, 141-162.

Huber, S. J., \& Cummings, J. L. (Eds.) (1992). Parkinson's disease: Neurobehavioral aspects. New York: Oxford University Press.

Kaplan, E., Goodglass, H., \& Weintraub, S. (1983). Boston Naming Test. Philadelphia: Lea \& Febiger.

LEVIN, S. (1984). Frontal lobe dysfunction in schizophrenia: I. Eye movement impairments. Journal of Psychiatric Research, 18, 27-55.

LeZAK, M. (1983). Neuropsychological assessment (2nd ed.). New York: Oxford University Press.

Posner, M. I., Early, T. S., Reiman, E., Pardo, P. L., \& DhaWAN, M. (1988). Asymmetries in hemispheric control of attention in schizophrenia. Archives of General Psychiatry, 45, 814-821.

RAO, S. M. (ED.) (1990). Neurobehavioral aspects of multiple sclerosis. New York: Oxford University Press.

Saykin, A. J., Gur, R. C., Gur, R. E., Mozley, P. D., Mozley, L. H., Resnick, S. M., Kester, B., \& Stafiniak, P. (1991). Neuropsychological function in schizophrenia: Selective impairment in memory and learning. Archives of General Psychiatry, 48, 618-624.

Spitzer, R. L., Williams, J. B. W., Gibbon, M., \& First, M. B. (1988). Instruction manual for the Structured Clinical Interview for DSM-III-R (SCID). New York: New York Psychiatric Institute.

Strauss, M. E. (1989). Cognitive markers for schizophrenia: An appraisal. In C. S. Schulz \& C. A. Tamminga (Eds.), Schizophrenia: Scientific progress (pp. 103-109). New York: Oxford University Press.

Thaker, G. K., Buchanan, R., KirkPatrick, B., \& Tamminga, C. A (1989). Oculomotor performance in schizophrenic illness. In C. S. Schulz \& C. A. Tamminga (Eds.), Schizophrenia: Scientific Progress (pp. 115-123). New York: Oxford University Press.

WECHSLER, D. (1981). Wechsler Adult Intelligence Scale-Revised $(W A I S-R)$. New York: Psychological Corporation.

(Manuscript received January 28, 1993.) 